\title{
Tradições Alimentares Regionais em uma América Latina Neocolonial: a luta pela manutenção de costumes e da soberania alimentar 1
}

\author{
Tradiciones Alimentarias Regionales en una América Latina Neocolonial: \\ la lucha por mantenimiento de las costumbres y soberanía alimentaria
}

\author{
Regional Food Traditions in a Neocolonial Latin American: the struggle \\ for the maintenance of customs and food sovereignty
}

\author{
Marcos Roberto Pisarski Junior ${ }^{1}$
}

\begin{abstract}
Resumo
A alimentação deve ser compreendida como expressão cultural de um grupo ou sociedade, sendo formada pela relação dialética entre a materialidade do acesso aos alimentos e da subjetividade de crenças, gostos e costumes. $\mathrm{Na}$ atual sociedade capitalista, a globalização impõe um modelo global de alimentação diretamente ligado aos interesses da produção alimentar voltada para o mercado, assim transformando alimentos em commodities. Este trabalho tem como objetivo apresentar e analisar as tradições alimentares regionais em contraposição as facetas da globalização nos hábitos alimentares e de suas relações com os modelos de produção de alimentos na América Latina. A metodologia utilizada nesta pesquisa se baseia em uma aprofundada revisão bibliográfica em trabalhos voltados a análise da alimentação como cultura, da globalização, das relações neocoloniais e conceitos de integração cultural da Latino-América, além da experiência do autor no tema de tradições alimentares em produções acadêmicas e na prática com vivências e visitas a grupos tradicionais e de resistência diretamente ligados a produção de alimentos e manutenção de costumes culturais, como: faxinalenses, quilombolas, indígenas e assentados de reforma agrária. Neste trabalho se possibilitou notar relações diretas entre o modelo de produção dos alimentos enquanto commodities no Brasil e demais países da américa latina, e a ameaça que isto representa perante a manutenção das tradições e da soberania alimentar, contribuindo assim à ideia de neocolonialismo, visto a implantação de um modelo de alimentação global. Conclui-se que a manutenção e resistência de tradições alimentares regionais encontra no modelo neocolonialista de produção de alimentos o seu antagonismo, assim transformando esta discussão em um objeto fundamental na defesa da soberania alimentar, costumes populares e do empoderamento de grupos tradicionais e de resistência, demonstrando assim que debates mais aprofundados e o desenvolvimento de políticas públicas são essenciais para a preservação destes elementos que constituem o povo latino-americano.
\end{abstract}

Palavras-Chave: Cultura; Neocolonialismo; Produção de Alimentos; Soberania Alimentar; Tradições Alimentares.

\section{Resumen}

\footnotetext{
'Artigo apresentado no Simpósio Temático 13 - Cultura, Fronteira e Relações Internacionais durante o II Seminário Latino-Americano de Estudos em Cultura - SEMLACult em Foz do Iguaçu/PR, Brasil, 2018.

2 Mestrando em Turismo, na linha Turismo, Sociedade e Meio Ambiente, do Programa de Pós-Graduação em Turismo da Universidade Federal do Paraná; Curitiba, Paraná, Brasil; marcos.pisarski@gmail.com
} 
La alimentación debe ser comprendida como expresión cultural de un grupo o sociedad, siendo formada por la relación dialéctica entre la materialidad del acceso a los alimentos y la subjetividad de creencias, gustos y costumbres. En la actual sociedad capitalista, la globalización impone modelos globales de alimentación directamente ligado a intereses de producción alimentaria volcada al mercado, transformando así alimentos en commodities. Esta pesquisa tiene como objetivo presentar y analizar las tradiciones alimentarias regionales en contraposición a las facetas de la globalización en hábitos alimentarios y sus relaciones con los modelos de producción de alimentos en Latinoamérica. La metodología utilizada en esta investigación se basa en revisión bibliográfica en trabajos sobre la alimentación como cultura, globalización, relaciones neocoloniales y conceptos de integración cultural latinoamericanas, además de experiencia del autor en el tema de tradiciones alimentarias con producciones académicas y práctica con vivencias y visitas a grupos tradicionales y de resistencia directamente ligados a producción de alimentos y mantenimiento de costumbres culturales, como: faxinalenses, quilombolas, indígenas y asentados de reforma agraria. En este trabajo se posibilitó notar relaciones directas entre el modelo de producción de alimentos como commodities en Brasil y demás países de Latinoamérica y la amenaza que esto representa ante el mantenimiento de las tradiciones y de la soberanía alimentaria, contribuyendo así a la idea del neocolonialismo con la implementación de un modelo de alimentación global. Se concluye que el mantenimiento y resistencia de las tradiciones alimentarias regionales encuentra en el modelo neocolonialista de producción de alimentos su antagonismo, transformando así esta discusión en objeto fundamental en la defensa de la soberanía alimentaria, costumbres populares y empoderamiento de grupos tradicionales y de resistencia, demostrando que debates más profundos y el desarrollo de políticas públicas son esenciales para la preservación de estos elementos que constituyen el pueblo latinoamericano.

Palabras Claves: Cultura; Neocolonialismo; Producción de Alimentos; Soberanía Alimentaria; Tradiciones Alimentarias.

\begin{abstract}
Food must be understood as a cultural expression of a group or society, being formed by the dialectical relation between the materiality of access to food and the subjectivity of beliefs, tastes and customs. In today's capitalist society, globalization imposes global models of food directly linked to interests of food production turned to the market, thus transforming food into commodities. This research aims to present and analyze the regional food traditions in contrast to the facets of globalization in food habits and their relations with the models of food production in Latin America. The methodology used in this research is based on bibliographical review in works on food such as culture, globalization, neocolonial relations and concepts of Latin American cultural integration, as well as the author's experience in the subject of food traditions with academic productions and practice with experiences and visits to traditional and resistance groups directly linked to food production and maintenance of cultural customs, such as: faxinalenses, quilombolas, natives and agrarian reform settlers. In this paper it was possible to note direct relations between the model of food production as commodities in Brazil and other Latin American countries and the threat that this represents to the maintenance of traditions and food sovereignty, thus contributing to the idea of neocolonialism with the implementation of a global food model. It is concluded that the maintenance and resistance of regional food traditions finds in the neocolonial model of food production their antagonism, transforming this discussion into a fundamental object in the defense of food sovereignty, popular customs and empowerment of traditional groups and resistance, demonstrating that deeper debates and the development of public policies are essential for the preservation of these elements that constitute the Latin American people.
\end{abstract}

Keywords: Culture; Neocolonialism; Food Production; Food Sovereignty; Food Traditions.

\title{
1. Introdução
}

A alimentação é, além de valores nutricionais, expressão cultural onde se materializam diversos aspectos históricos, econômicos, geográficos e antropológicas de um grupo social. Segundo Matta (1986, p.56), comida não é apenas uma substância alimentar, mas é também um modo, um estilo e um jeito de alimentar-se. E o jeito de comer define não só aquilo que é ingerido, como também aquele que o ingere. 
Os elementos materiais e subjetivos da alimentação são intrinsicamente relacionados as diversas interfaces do meio social onde a tradição alimentar é reproduzida, entre elas as dinâmicas de produção de determinados alimentos, a distribuição e a relação financeira atribuídas a eles, e o consumo, ou não consumo, de determinados alimentos.

No mundo globalizado atual, onde na América Latina se sobressai a lógica imperialista neocolonial, as tradições alimentares regionais sofrem com diversos ataques em suas diferentes etapas de manutenção, dentre elas se destacam os obstáculos na produção dos alimentos, onde por imposição do mercado determinados produtos são priorizados em relação a outros. (MOOZ e PISARSKI JUNIOR, 2017)

Desta forma, é criada uma lógica de produção que atende somente as necessidades do mercado, priorizando o cultivo de arroz, cana de açúcar, trigo, milho e soja onde são em sua maioria consumidas pelas grandes industrias do agronegócio, nas quais as populações regionais se tornam submissas. (GIRARDI, RIBEIRO e PAULI, 2014)

Estes personagens, que Ploeg (2008) também chama de impérios alimentares, transformam os alimentos produzidos em commodities, não levando em consideração os costumes e tradições alimentares das populações onde agem, fazendo com que diversos alimentos deixem de ser produzidos, e por consequência consumidos, fadando-os ao esquecimento e extinção.

Na contramão deste processo existem os grupos de resistência que, mesmo que não tragam como prioritária a pauta da manutenção e preservação dos costumes e tradições alimentares, elas estão diretamente relacionadas as suas principais lutas, como por exemplo no caso dos grupos que defendem a reforma agrária esta a pauta da agroecologia, nos grupos faxinalenses e quilombolas a manutenção de suas tradições culturais, entre elas as alimentares.

Ao longo deste trabalho, são debatidas as ideias expostas acima com uma exposição teórica mais aprofundada, onde são relacionados e confrontados alguns pontos que fazem parte da linha condutora do debate da luta pela manutenção das tradições alimentares e da soberania alimentar na a atual conjuntura econômica e social da América Latina.

\section{Produção, Soberania e Cultura alimentar.}


A alimentação é um elemento central na sociedade humana desde os primórdios até os dias atuais. Ela consiste em uma das principais necessidade fisiológica do corpo mas que ganha diferentes aspectos culturais, econômicos e de poder, além de ter sido (e sempre será) um personagem central na história da humanidade, sendo agente de conflitos, guerras, disputas econômicas, paz e rituais sociais.

Dentre estes grandes aspectos que envolvem a alimentação humana, alguns deles requerem uma análise mais aprofundada visto sua complexidade, especialmente nos dias atuais, onde vivemos um neoliberalismo econômico que atua diretamente nos mais variados aspectos da sociedade.

A seguir, alguns destes aspectos serão destrinchados com finalidade de fornecer uma melhor analise que colabore com a ideia central deste trabalho.

\subsection{Alimentação como cultura}

É necessário observar a alimentação além de como uma necessidade básica para o ser humano, também considerado como o primeiro e "ato histórico" para a reprodução da vida, como afirma Marx e Engels (1987, p.39) "os homens devem estar em condições de viver para poder 'fazer história'. Mas, para viver, é preciso antes de tudo comer, beber, ter habitação, vestir-se e algumas coisas mais.".

Desta forma, o alimento e o ato de se alimentar devem ser analisadas por outras perspectivas além de ser fonte nutricional biológica, entre elas o de objeto e elemento cultural. Neste sentido Santos (2006) aponta:

Os alimentos não são somente alimentos. Alimentar-se é um ato nutricional, comer é
um ato social, pois constitui atitudes ligadas aos usos, costumes, protocolos,
condutas e situações. Nenhum alimento que entra em nossas bocas é neutro. A
historicidade da sensibilidade gastronômica explica e é explicada pelas
manifestações culturais e sociais, como espelho de uma época e que marcaram uma
época. Nesse sentido, o que se come é tão importante quanto quando se come, onde
se come, como se come e com quem se come. (p. 1)

O alimento, assumindo esta condição de elemento social e cultural pode ser visto e interpretado de outras formas. Neste sentido, Montanari (2014) afirma a respeito da relação entre alimento e cultura: 
Comida é cultura quando consumida, porque o homem, embora podendo comer de tudo, ou talvez justamente por isso, na verdade não come qualquer coisa, mas escolhe a própria comida, com critérios ligados tanto às dimensões econômicas e nutricionais do gesto quanto aos valores simbólicos de que a própria comida se reveste. Por meio de tais percursos, a comida se apresenta como elemento decisivo da identidade humana e como um dos mais eficazes instrumentos para comunicá-la.

Estes pontos quando observados de forma social, indicam que alimentos iguais podem ter significado, gostos e consumo diferentes em sociedades diferentes, mostrando que há uma subjetividade social nesta relação alimento-sociedade.

Na subjetividade de cada cultura há gostos e sabores específicos que não limitam suas propriedades às relações sensoriais. Estes elementos vão muito além do gosto e passam por campos religiosos, biológicos, de costumes populares e relações sociais de poder. Construído assim "gostos sociais" particulares para cada povo, etnia ou grupo social.

Portanto, assim podemos observar que a alimentação carrega consigo muito mais que apenas valores nutricionais, mas uma bagagem social, histórica e cultural imensurável, e é um elemento central na dialética e na dinâmica social do mundo, desde em anos mais distantes quanto nos globalizados atuais.

\section{2 Produção e Consumo Alimentar}

No debate de globalização, é possível compreender a interface dela com a alimentação como um elemento que impõe padrões e padronizações em hábitos e tradições culturais, homogeneizando estas relações e aumento os impactos e influência do capitalismo na reprodução social. (SANTOS, 2006)

Entre alguns dos aspectos que sofrem dessa influência da globalização capitalista, podemos afirmar que a alimentação é uma expressão material desse processo predador e homogeneizador na cultura de um povo. Ele pretende assim transformar os aspectos culturais em produtos ou os transforma em “commodities”. (HARVEY, 2005; PLOEG, 2008)

Essa parte do processo da globalização que pretende homogeneizar os hábitos e costumes culturais foi batizado de McDonalização, devido a relação de padronizar questões culturais subjetivas. Este termo é utilizado nos diversos âmbitos culturais da nossa sociedade, principalmente no debate sobre hábitos e costumes alimentares. (RITZER, 2004) 
Este processo de McDonalização da vida padroniza os hábitos alimentares e impõem lógicas de consumo que contribuam com as do mercado, assim incentivando o consumo de produtos industrializados e commodities em nosso dia-a-dia, fazendo com que isso seja também atrelado as outras etapas da alimentação, principalmente na produção de alimentos.

Aliado a este ponto, outra teoria que tem intensa relação com a produção e, principalmente, com o consumo alimentar atual é a teoria dos Regimes Alimentares, descritos por McMichael (2009), nela o autor define períodos onde hegemonias econômicas decidiam o consumo mundial de gêneros alimentícios: o primeiro onde o Império Britânico detinha o monopólio dos alimentos importados das suas colônias; o segundo surge no pós II Guerra Mundial, na ocasião da Guerra fria onde os Estados Unidos regulava a balança econômica mundial e intervinha diretamente nos produtos consumidos (entre eles os alimentos); e a terceira e atual fase onde as grandes corporações decidem, com base no lucro, quais alimentos devem ser consumidos em larga escala. (McMICHAEL, 2009)

Como exemplo deste impacto na produção de alimentos, exemplifica Santos (2006, p. 12), "hoje nossa alimentação se baseia em poucas espécies: menos de 30 plantas são responsáveis pela alimentação de $95 \%$ da população."

Aliado a isso, o neocolonialismo trata de impor a ideia de que os países da América Latina são meros latifúndios para suprir a necessidade alimentares de seus países e matéria prima para a produção de alimentos industrializados e rações de suas multinacionais (PRADO JUNIOR, 1979)

Um grande exemplo desta relação entre o padrão Mcdonalizado de consumo e a produção das grandes commodities é o fato de que a soja, o milho e o trigo estão na composição da grande maioria dos produtos alimentares consumidos no dia a dia, como no óleo, macarrão, salgadinhos, comidas congeladas, refrigerantes, cervejas e muitos outros.

Colaborando com esta ideia apresentada, Gomes Junior e Aly Junior (2015) afirmam que:

$\mathrm{Na}$ atualidade, soja, milho, trigo e arroz respondem em média por pelo menos dois terços da ingesta calórica diária, caloria barata na forma das mais bizarras substâncias alimentares, além dos preparos tradicionais, tudo em embalagens práticas, coloridas, e acima de tudo, baratas quando confrontadas com os preços da comida de verdade. (p. 312) 
Com estes dados expostos é possível afirmar o antagonismo das tradições alimentares e da soberania alimentar com o agronegócio, sendo este o principal personagem que os ataca em suas diferentes etapas: produção, distribuição e consumo.

Na contramão deste processo, a soberania alimentar surge como bandeira essencial no processo de enfrentamento e resistência a esta prática econômica, de produção e gestão ambiental predatória. Para ter mais clareza do conceito exposto como soberania alimentar, utiliza-se a definição da Via Campesina Internacional exposta como declaração final no Fórum Mundial de Soberania Alimentar de 2001:

O direito dos povos de definir suas próprias políticas e estratégias sustentáveis de produção, distribuição e consumo de alimentos que garantam o direito à alimentação para toda a população com base na pequena e média produção, respeitando suas próprias culturas e a diversidade de modos camponeses, pesqueiros e indígenas de produção agropecuária, de comercialização e de gestão dos espaços rurais, nos quais a mulher desempenha um papel fundamental. A soberania alimentar favorece a soberania econômica, política e cultural dos povos. Defender a soberania alimentar é reconhecer uma agricultura com camponeses, indígenas e comunidades pesqueiras, vinculadas ao território; prioritariamente orientada à satisfação das necessidades dos mercados locais e nacionais.

Por tanto, esta relação da produção e do consumo alimentares devem ser tratados de forma conjunta visto as profundas relações de

Neste contexto, os grupos de resistência surgem como possíveis agentes no processo de mitigar os impactos do neocolonialismo na produção dos alimentos. Grupos organizados e movimentos sociais que defendem a reforma agrária e agroecologia, como a ANZORC, da Colômbia, ATC, da Nicarágua, MOCASE, da Argentina, a MCP, do Paraguai, a UNORCA, do México ou o MST, no Brasil, são agentes centrais na luta contra a lógica latifundiária do campo Latino-americano frente ao capitalismo internacional e neocolonial.

Para ilustrar esta relação, segue a afirmação da ANZORC (2012) no Fórum Agrário da Colômbia:

Tenemos derecho y podemos ejercer el poder, el poder que desde la base enriquece a toda la sociedad. En ejercicio de ese poder hemos sobrevivido las comunidades rurales, hemos intentado domar la naturaleza y nos hemos dejado domesticar por ella, hemos aprendido sus secretos y sus lecciones, hemos construido comunidad, consensuando normas propias, produciendo alimentos, organizándonos a partir de la solidaridad, para sobrevivir al destierro, a la exclusión, al abandono estatal, al olvido social, y al terror del Estado y las clases dominantes. 
No mesmo sentido desde grupos em defesa da reforma agrária, encontramos os faxinalenses. Estes são um grupo tradicional de resistência que priorizam a coletivização de suas terras e a produção agrícola que não se a lógica do agronegócio.

Por essa lógica de pouca importância mercadológica, central no agronegócio, Chang (1988, p.107) afirma, no Sistema Faxinal há uma coletivização do uso das terras de criação. Este espírito de coletivização é antagônico à racionalidade da produção capitalista, onde o privado é tido como pressuposto inviolável e inquestionável. (CHANG, 1988)

Dentro das comunidades de faxinais é possível, por exemplo, observar outra relação com o modo de criação dos animais. Nestes lugares os animais ficam livres de cercas, galinheiros, currais e chiqueiros, são criados soltos por todas as terras compartilhadas e assim vivem de forma menos industrializada, o que mais uma vez não corresponde à lógica capitalista.

Conclui-se então que estes grupos de resistência fazem frente a lógica globalizada neoliberal, sendo agentes centrais na luta pela preservação da soberania e tradições alimentares regionais.

\section{Conclusões}

Como exposto e explicitado ao longo do trabalho, são apontadas algumas ideias de como pode ser possível interpretar a questão das tradições alimentares, como elemento cultural, em contraposição a lógica de produção alimentar do campo e a imposição de um regime alimentar seguindo os padrões culturais e econômicos da globalização.

É possível concluir que a produção agrícola de monocultura de commodities é um dos principais vilões da relação entre a preservação de culturas e tradições alimentares com a produção de alimentos que permitam que estas bandeiras existam de forma plena e natural na atual sociedade.

Defender a soberania alimentar é ser resistência ao regime alimentar global e a produção agroindustrial em larga escala no campo latino americano. Sendo isso uma bandeira política de sobrevivência e manutenção da subjetividade cultural de todos os povos latinoamericanos.

Algumas das possíveis formas de lidar com esta situação e defender a bandeira da soberania alimentar na américa latina neocolonial atual é a defesa da agricultura familiar 
agroecológica, reforma agraria dos latifúndios pertencentes as grandes corporações agroindustriais e incentivo e luta por políticas públicas que defendam os pequeno agricultores e impeçam que sejam reféns das grandes corporações agroindustriais com suas sementes transgênicas e modificadas.

Também é necessário pautar uma educação alimentar nas redes de educação básica e na educação alternativa, fazendo que as futuras gerações vejam os malefícios da monocultura de commodities e de como as diferentes culturas alimentares e diferentes tipos vegetais devem ter tratados na sociedade atual.

Os movimentos sociais, que nos tempos atuais, sofrem devido a perseguições e demonização política frente a onda reacionária atual, devem cumprir seu papel de resistência nesta sociedade e ser abraçados pela sociedade critica a fim de potencializar as lutas sociais do campo e, de forma dialética, permitir que tradições e culturas alimentares sejam mantidas e conservadas.

Com esta forma é possível potencializar as pautas da alimentação na região da América Latina, fazendo com que as tradições alimentares regionais sejam incentivadas e preservas de forma qualificada e com maior abrangência a diferentes públicos.

\section{Referências}

CAMACHO. R. S. O agronegócio latifundiário versus a agricultura camponesa: a luta política e pedagógica do campesinato. In: Anais do XIX Encontro Nacional de Geografia Agrária, São Paulo, 2009, p. 1-34

CHANG, M. Y. Sistema Faxinal: Uma forma de organização camponesa em desagregação no Centro-sul do Paraná. Londrina: IAPAR,1988, 124f. (Boletim no 22)

CHONCHOL, J. A Soberania Alimentar. Dossiê América Latina. Estudos avançados, vol. 19, $n^{\circ}$ 55, São Paulo, set-dez/2005.

GIRARDI, E. P.; RIBEIRO, E. S.; PAULI, L. Dinâmicas Recentes do Campo Brasileiro: Atualização e Aprimoramento do Atlas da Questão Agrária Brasileira. 2014. 12 f. - Curso de Geografia, Universidade do Estado de São Paulo, São Paulo, 2014.

GOMES JUNIOR, N. N.; ALY JUNIOR, O. Soberania Alimentar e Agronegócio: Notas Além da Porteira. Revista Eletrônica Retratos de Assentamentos, v. 18, n. 2, 2015.

HARVEY, D. A brief history of neoliberalism. Oxford: Oxford University Press; 2005. 
MATTA, R. O que faz o Brasil, Brasil?, Rio de Janeiro: Rocco; 1986.

MCMICHAEL, P. A food regime genealogy. The Journal of Peasant Studies. Vol. 36, $\mathrm{n}^{\mathrm{o}} 1$, January 2009.

MONTANARI, M. Comida como cultura: tradução de Letícia Martins de Andrade. São Paulo: editora SENAC: 2008

MOOZ, P. F. P.; PISARSKI JUNIOR, M. R. O sistema faxinal como mecanismo mitigador dos impactos da globalização nas tradições alimentares In: Anais do VIII Simpósio Internacional de Geografia Agrária, Curitiba, 2017.

PLOEG, J. D. V. D. Camponeses e impérios alimentares: lutas por autonomia $e$ sustentabilidade na era da globalização. Porto Alegre: Editora da UFRGS, 2008.

PRADO JR, Caio. Sentido da colonização. Formação do Brasil contemporâneo: colônia. São Paulo: Brasiliense, 1979.

RITZER, G. The McDonaldization of society. Thousand Oaks, CA: Pine Forge Press; 2004.

SANTOS, C. R. A. O Império Mcdonald e a Mcdonalização da Sociedade: Alimentação, Cultura e Poder. Seminário facetas do império na história, 2006 nov. Disponível em: http://people. ufpr.br/ andreadore/antunes.pdf. Acesso em: 29 de maio de 2017.

SANTOS, M. Por uma outra globalização: do pensamento único à consciência universal. 13. ed. Rio de Janeiro: Record, 2006.

VIA CAMPESINA. Declaração final do Fórum Mundial de Soberania Alimentar; Havana, Cuba/2001. Disponível em: http://www.social.org.br/cartilhas/cartilha003/ 